\title{
Temperature influence study on copper selenide films
}

\author{
V. Rajendran ${ }^{1}$, S. Arulmozhi Packiaseeli ${ }^{2}$, S. Muthumari ${ }^{3}$ and R. Vijayalakshmi ${ }^{3}$ \\ ${ }^{1}$ Department of Physics, Vivekananda College, Madurai 625234, India \\ ${ }^{2}$ P. G. \& Research Department of Physics, Fatima College, Madurai 625018, India \\ ${ }^{3}$ P. G. \& Research Department of Physics, Thiagarajar. College, Madurai 625009, India \\ rajendran.vvc@gmail.com,ramyarv@rediffmail.com
}

PACS 74.25 Gz, $64.70 \mathrm{ph}, 61.05 \mathrm{Cp}$

DOI 10.17586/2220-8054-2016-7-4-699-702

Copper selenide was prepared by film is successfully deposited on a Fluorine-doped Tin Oxide (FTO) substrate by a brush plating technique. The film was uniform, had good adherence to the substrate and was annealed at $300{ }^{\circ} \mathrm{C}$ and $500{ }^{\circ} \mathrm{C}$. As the annealing temperature increased, the orientation of the crystallites is more randomized than in the as-prepared film. The structural and optical properties of the film were investigated by XRD, SEM, EDAX, UV-Visible and PL. The XRD pattern indicated that this film was crystalline in the structure.

Keywords: Brush plating, copper selenide, optical properties.

Received: 5 February 2016

Revised: 3 May 2016

\section{Introduction}

Copper selenide $\left(\mathrm{Cu}_{2} \mathrm{Se}\right)$ thin films have attracted considerable interest over the last year owing their wide range of applications in optoelectronic devices and solar cells. Copper selenide is an interesting metal chalcogenide semiconductor material. A copper selenide thin film has a direct band gap and is transparent over a wide range of the visible spectrum. It is seen that the photoelectronic and other properties of II-VI class of compound thin films are highly optically-sensitive, which in turn, can severely influence device performance [1]. More progress has been achieved in the fabrication of light emitting diodes, dielectric mirrors and other optically sensitive devices.

Selenium-based alloys are not stable under standard operational conditions because their glass transitions are typically close to room temperature. In order to stabilize these glasses it is common to use an additive which acts as a cross-linking agent and increase the dimensionality of structure and stability of the material [2]. The purpose of present study is to explore and report in detail the structural properties and optical properties of copper selenide thin film prepared by brush plating technique.

\section{Experimental procedure}

The precursor solution was prepared by stirring $1 \mathrm{~g}$ of copper(II) sulfate $\left(\mathrm{CuSO}_{4}\right)$ and 0.05 gm of selenium dioxide $\left(\mathrm{SeO}_{2}\right)$ in $5 \mathrm{ml}$ of distilled water until the powder is totally mixed to provide a saturated solution. The Copper Selenide thin films were prepared by Brush Plating technique. The films were grown on Fluorine doped Tin Oxide (FTO) substrate under optimized conditions. These grown films were uniform, blue in color and showed good adherence to the substrate surface. All chemicals were of AR grade.

The as-deposited films were annealed at $300{ }^{\circ} \mathrm{C}$ and $500{ }^{\circ} \mathrm{C}$ for about $1 \mathrm{hr}$. The annealed film was utilized for optical- and structural properties studies.

\section{Results and discussion}

\subsection{XRD Analysis}

Figures 1(a) and (b) show the X-ray diffraction pattern of the brush plated copper selenide thin film. The XRD pattern obtained correlated well with the standard JCPDS (06-680) data.

Crystallite size $(D)$ was calculated using Debye-Scherrer's formula [3]:

$$
D=0.94 \lambda / \beta \cos \theta
$$

where $D$ is the crystallite size, $\lambda$ is the wavelength of the $k_{\alpha}$ line, $\beta$ is the full width at half maxima (FWHM) in radians and $\theta$ is the Bragg's angle. The crystallite grain size increased from $2-53 \mathrm{~nm}$ as the annealing temperature increased [4]. The observed 'd' values 4.5, 2.2, 2.0, $1.5 \AA$ are in good agreement with the standard 'd' values. Peaks corresponding to $\left(\begin{array}{lll}1 & 1 & 0\end{array}\right),\left(\begin{array}{lll}2 & 2 & 0\end{array}\right),\left(\begin{array}{lll}3 & 1 & 0\end{array}\right),\left(\begin{array}{lll}4 & 0 & 1\end{array}\right)$ were observed [5]. 


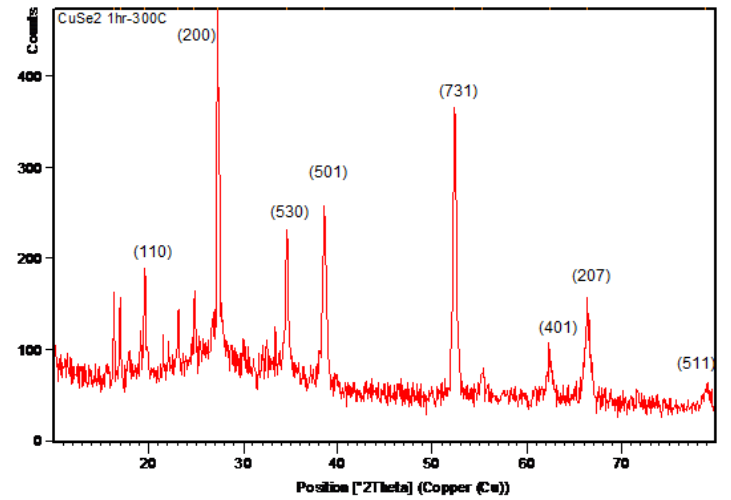

(a)

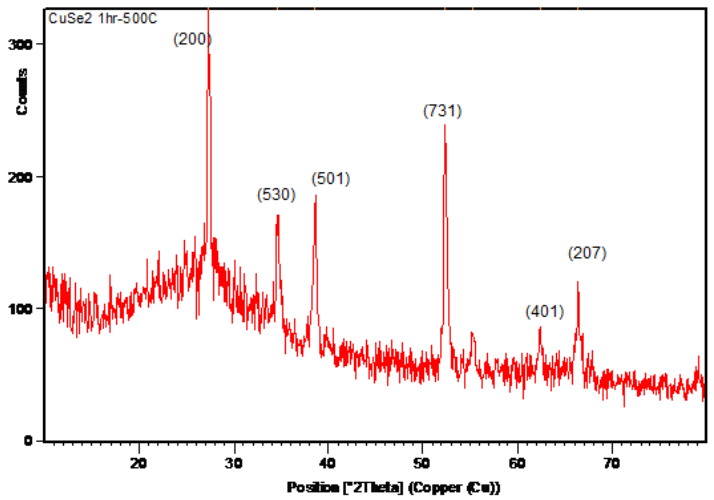

(b)

FIG. 1. XRD pattern of $\mathrm{Cu}_{2}$ Se thin film annealed at $300{ }^{\circ} \mathrm{C}$ (a) and $500{ }^{\circ} \mathrm{C}$ (b)

\subsection{Morphological studies and compositional analysis}

Scanning electron microscopy is a convenient tool to study the surface morphology of micro- and nanoscale materials as well as thin films. Fig. 2(a,b) shows the SEM images of CuSe thin films annealed at $300{ }^{\circ} \mathrm{C}$ and $500{ }^{\circ} \mathrm{C}$ recorded at $20 \mathrm{kV}$ with the magnification 10000 using the instrument JSM-6390. The particle size increased as the annealing temperature increased [6].

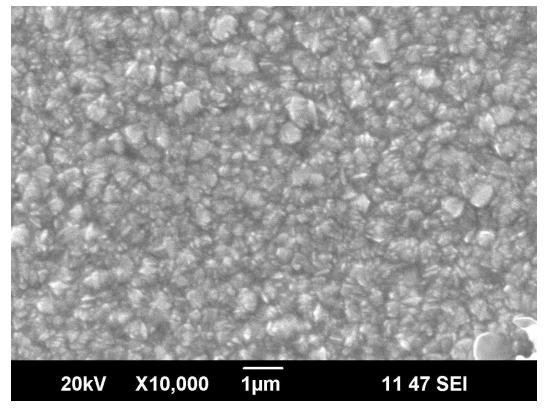

(a)

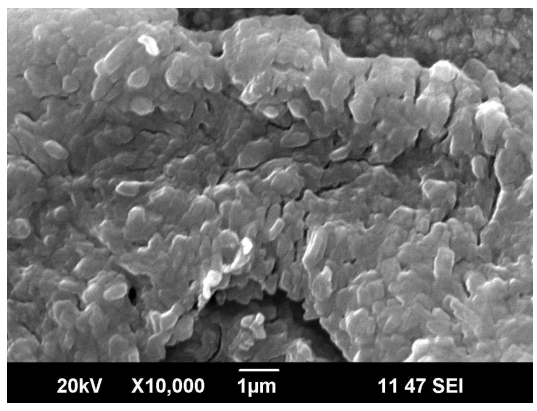

(b)

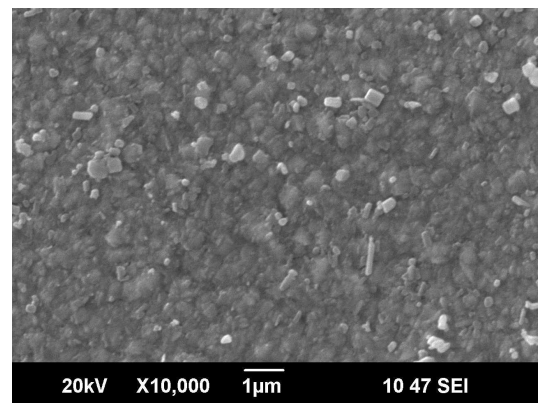

(c)

FIG. 2. SEM image of $\mathrm{Cu}_{2} \mathrm{Se}$ as deposited (a); annealed at $300{ }^{\circ} \mathrm{C}$ (b) and $500{ }^{\circ} \mathrm{C}$ (c)

The EDAX analysis from Fig. 3(a-c) revealed that the presence of copper, selenium, oxygen and other elements like silicon, tin on the FTO substrate. The EDAX spectrum recorded in the binding energy region of $0-10 \mathrm{keV}$ showed the presence of copper and selenium in thin films. EDAX analysis of the mass $\%$ and atom $\%$ of copper selenide films are tabulated in Table 1. EDAX spectrum confirms the presence of copper and selenium in the thin films [7].

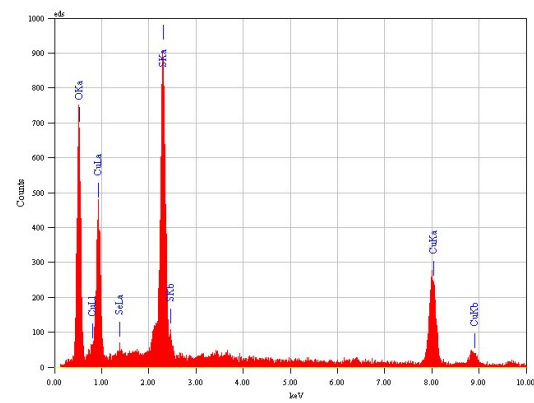

(a)

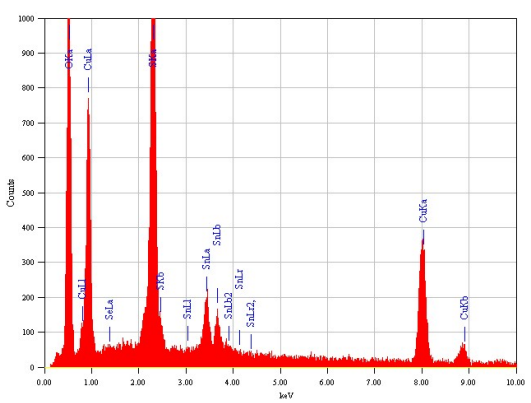

(b)

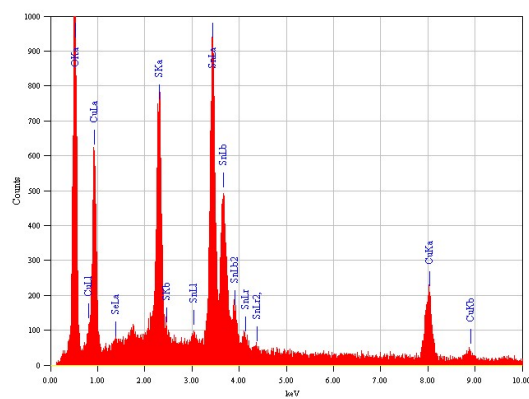

(c)

FIG. 3. EDAX analysis of $\mathrm{Cu}_{2} \mathrm{Se}$ as deposited (a); annealed at $300{ }^{\circ} \mathrm{C}$ (b) and $500{ }^{\circ} \mathrm{C}$ (c) 
TABle 1. Mass and Atom percentage of $\mathrm{Cu}_{2}$ Se annealed at $300{ }^{\circ} \mathrm{C}$ and $500{ }^{\circ} \mathrm{C}$

\begin{tabular}{|c|c|c|c|c|}
\hline \multirow{2}{*}{ Sample } & \multicolumn{2}{|c|}{ Mass \% } & \multicolumn{2}{c|}{ Atom \% } \\
\cline { 2 - 5 } & Copper & Selenium & Copper & Selenium \\
\hline As-deposited & 49.35 & 1.19 & 26.23 & 0.51 \\
\hline Annealed at $300{ }^{\circ} \mathrm{C}$ & 38.73 & 0.42 & 21.78 & 0.19 \\
\hline Annealed at $500{ }^{\circ} \mathrm{C}$ & 16.37 & 0.41 & 12.89 & 0.26 \\
\hline
\end{tabular}

\subsection{Optical absorption, transmittance and reflectance measurement}

The typical optical absorbance, transmittance $T(\%)$ spectra and reflectance spectra of the films prepared using brush plating method are presented in Fig. $4(\mathrm{a}-\mathrm{c})$ respectively for the as-deposited and annealed samples $\left(\right.$ at $300{ }^{\circ} \mathrm{C}$ and $500{ }^{\circ} \mathrm{C}$ ). Annealing the film at $300{ }^{\circ} \mathrm{C}$ and $500{ }^{\circ} \mathrm{C}$ resulted in some changes in the optical transmittance and absorbance spectra of the films.

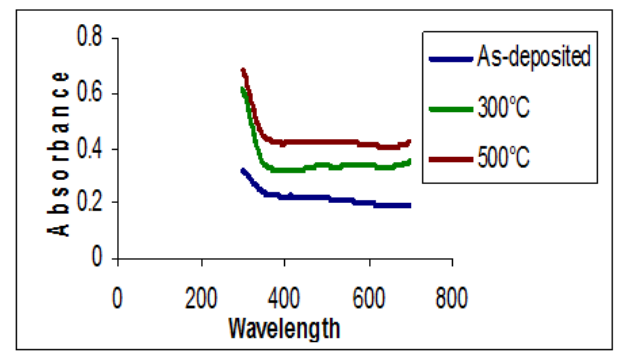

(a)

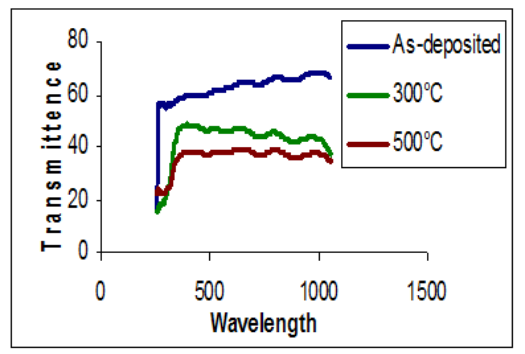

(b)

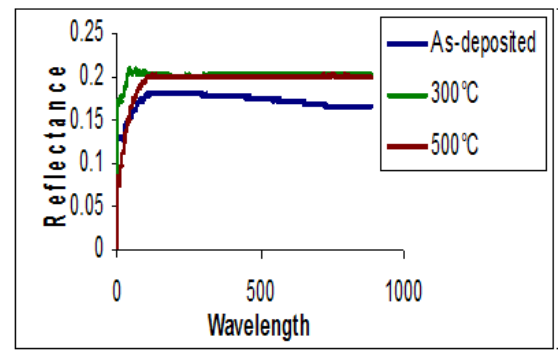

(c)

FIG. 4. Absorption (a), transmittance (b) and reflectance (c) spectra for $\mathrm{Cu}_{2} \mathrm{Se}$

The Egdir values for the samples were as follows: as-deposited $-2.95 \mathrm{eV} ; 300{ }^{\circ} \mathrm{C}$ annealing $-2.86 \mathrm{eV}$ and $500{ }^{\circ} \mathrm{C}$ annealing $-2.75 \mathrm{eV}$. The Egind values were as follows: as-deposited $-2.16 \mathrm{eV} ; 300{ }^{\circ} \mathrm{C}$ annealing $2.54 \mathrm{eV}$ and $500{ }^{\circ} \mathrm{C}$ annealing $-2.38 \mathrm{eV}$. The indirect band gap values were as follows: re as-deposited $-2.16 \mathrm{eV}$; $300{ }^{\circ} \mathrm{C}$ annealing $-2.54 \mathrm{eV}$ and $500{ }^{\circ} \mathrm{C}$ annealing $-2.38 \mathrm{eV}$. All these optical band gap values are close to those previously obtained for the material used for solar cells, which means that these materials have good utility for this purpose [8].

\subsection{Photoluminescence spectrum}

The photoluminescence spectra of $\mathrm{Cu}_{2} \mathrm{Se}$ thin films are shown in Fig. 5. From the spectra, the photons are excited at a wavelength of $280 \mathrm{~nm}$. As the annealing temperature increases, the intensity of the peak increases. From the spectra, the peaks observed in emission of $\mathrm{Cu}_{2} \mathrm{Se}$ thin films are at a wavelength $561 \mathrm{~nm}$ [9]. The spectra of the as-deposited $\mathrm{Cu}_{2} \mathrm{Se}$ films and the annealed films showed increasing intensity as the annealing temperature increased.

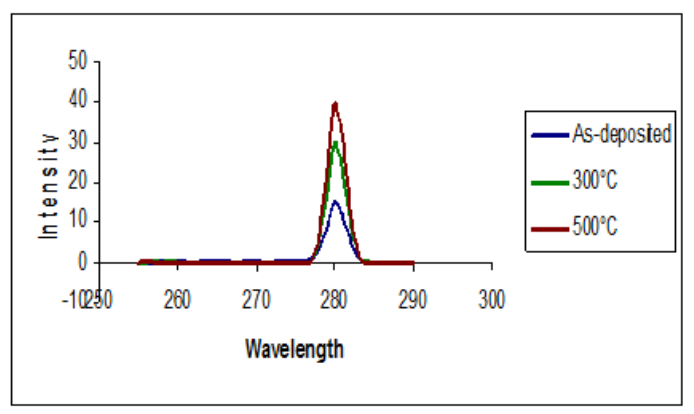

FIG. 5. Excitation Spectra of $\mathrm{Cu}_{2} \mathrm{Se}$ 


\section{Conclusion}

Copper Selenide thin films were successfully deposited on FTO substrates by a brush plating technique. The films were uniform and had good aherence to the substrate. The XRD of Copper Selenide films formed a cubic structure. The crystalline size of the films were determined by Scherrer's formula and it increased from $2-53 \mathrm{~nm}$ as the annealing temperature increased [10]. The energy gap values of the films were determined and compared with the reported one. The emitted and excited wavelength were determined from the photoluminescence spectra. The structural properties, surface morphological studies and chemical composition analysis were investigated and reported.

\section{References}

[1] Vipin kumar, Vinod Kumar, Dwivedi D.K. Growth and characterization of zinc telluride thin films for photovoltaic applications. Physica Scripta, 2012, 86, 015604 (4 p.)

[2] Vijayalaksmi R., Chandrasekar L. Bruno, Chandramohan R. Preparation and Characterization of Se-Te-Ag Chalcogenide Thin Film. Journal of Nanoengineering and Nanomanufacturing, 2013, 3, P. 70-72.

[3] Hammad Jamil T.M., Salem K., Harrison R.G. Binding agent affect on the structural and optical properties of ZnO nanoparticles. Rev. Advanced Material Science, 2009, 22, P. 74-80.

[4] Ramesh K., Thanikaikarasan S., Bharathi B. Structural, morphological and optical properties of copper selenide thin films. International Journal of Chem. Tech. Research, 2014, 6 (13), P. 5408-5411.

[5] Garcia V.M., Nair P.K., Nair M.T.S. Binding Agent affect on the Structural and Optical Properties of ZnO nanoparticles. Journal Of Crystal Growth, 1999, 203, P. 113-124.

[6] Thi Die Thuy Ung, Quang Liem Nguyen. Structural, Morphological and Optical Properties of Copper Selenide Thin Films. Adv. Nat. Sci: Nanosci. Nanotechnol., 2011, 2, 045003.

[7] Mehta N., Zulfequar M., Kumar A., Crystallization kinetics of some Se-Te-Ag chalcogenide glasses. Journal of Optoelectronics and Advanced Materials, 2004, 6, P. 441.

[8] Arokiya Mary T., et al. A simple hydrothermal route for synthesizing copper Selenide Nano-Flakes. Elixir Nanocomposite Materials, 2012, 50, P. 10499-10500.

[9] Garcia V.M., Guerrero L., Nair M.T.S., Nair P.K. Effect of thermal processing on optical and electrical properties of copper selenide thin films. Superficies y Vacio, 1999, 9, P. 213-218.

[10] Arulmozhi Packiaseeli S., Rajendran V., Vijayalakshmi R. Structural, optical and morphological study of tungsten selenide thin films. Nanosystems: Physics, Chemistry, Mathematics, 2016, 7 (4), P. 703-706. 